UNIVERSIDADE DE SÃO PAULO

FACULDADE DE EDUCAÇÃO

CLARISSA SILVA DE CASTILHO

O espaço escolar como mediador simbólico: cultura, experiência e sentidos

SÃO PAULO 

CLARISSA SILVA DE CASTILHO

\section{O espaço escolar como mediador simbólico: cultura, experiência e sentidos}

Tese apresentada à Faculdade de Educação da Universidade de São Paulo como requisito para obtenção do título de Doutora em Educação. Área de Concentração: Psicologia e Educação Orientadora: Profa. Livre Docente Teresa Cristina Rego 
AUTORIZO A REPRODUÇÃO E DIVULGAÇÃO TOTAL OU PARCIAL DESTE TRABALHO, POR QUALQUER MEIO CONVENCIONAL OU ELETRÔNICO, PARA FINS DE ESTUDO E PESQUISA, DESDE QUE CITADA A FONTE.

Catalogação na Publicação

Serviço de Biblioteca e Documentação

Faculdade de Educação da Universidade de São Paulo

371.6

C352e
Castilho, Clarissa Silva de

O espaço escolar como mediador simbólico: cultura, experiência e sentidos / Clarissa Silva de Castilho; orientação Teresa Cristina Rego. São Paulo: s.n., 2014.

345 p. ils.; anexos; apêndices

Tese (Doutorado - Programa de Pós-Graduação em Educação. Área de Concentração: Psicologia e Educação) - Faculdade de Educação da Universidade de São Paulo.

1. Espaço escolar 2. Relação aluno-escola 3. Semiótica da arquitetura 4. Cultura escolar 5. Escola pública 6. Escolarização I. Rego, Teresa Cristina, orient. 
Nome: CASTILHO, Clarissa Silva de.

Título: O espaço escolar como mediador simbólico: cultura, experiência e sentidos.

Tese apresentada à Faculdade de Educação da Universidade de São Paulo (área de concentração Psicologia e Educação) para obtenção do título de Doutora em Educação.

Aprovado em:

Banca Examinadora

Prof. Dr. Instituição:

Julgamento: Assinatura:

Prof. Dr. Instituição:

Julgamento: Assinatura:

Prof. Dr. Instituição:

Julgamento: Assinatura:

Prof. Dr. Instituição:

Julgamento: Assinatura:

Prof. Dr. Instituição: 

À minha mãe, que para minha vida criou um mundo.

A meu filho, que o esgarça e me arrebata em novas criações. 



\section{AGRADECIMENTOS}

Ao Mauro, por esperar.

Ao Francisco, pelo amor sensível.

À minha mãe, Marisa, por cuidar.

Ao Vlad, principal colaborador dessa pesquisa e irmão amado, por estar junto.

À Ondina e ao Fred porque sempre seremos (ao menos) "seis".

Ao meu pai, Édson, pelas saudades.

Aos amigos, porque vão e vêm.

Aos meus alunos, pelo entusiasmo e por dar-me a chance de viver a Educação.

À turma do GEPAE, pelos ideais compartilhados e por rir.

À Maiara Quaglio, Raquel Pires, Ana Paula Renesto, Maria Aparecida Guedes Monção e Cileda Perrela pelas inestimáveis contribuições e apoio nos momentos cruciais.

À EE Amadeu Amaral, por abrir as portas, todas; e à Luíza, por ter as chaves (e por sua cooperação e afeto genuínos).

À FEUSP, por propiciar o caminho.

$\mathrm{E}$

À Teresa... por tanto!

pelo encontro com a mestra e a pessoa

pelo arrojo intelectual

pela inquietude investigativa

pelo olhar paciente e amoroso

...e pelo sorriso confiante! 

Entre duas notas de música existe uma nota, entre dois fatos existe um fato, entre dois grãos de areia por mais juntos que estejam existe um intervalo de espaço, existe um sentir que é entre o sentir - nos interstícios da matéria primordial está a linha de mistério e fogo que é a respiração do mundo, e a respiração contínua do mundo é aquilo que ouvimos e chamamos de silêncio. 



\section{RESUMO}

CASTILHO, Clarissa. O espaço escolar como mediador simbólico: cultura, experiência e sentidos. 2014. 345 f. Tese (Doutorado em Educação) - Faculdade de Educação, Universidade de São Paulo, São Paulo, 2014.

A partir do construto de mediação simbólica de Vigotski, entendida como intrínseca ao processo de desenvolvimento psíquico e cultural humano, esta pesquisa, de cunho qualitativo, investigou o espaço escolar enquanto mediador de significados e sentidos sobre a escola, tanto pelo que propõe sua configuração arquitetônica quanto pelas experiências e usos que possibilita ou que se faz desse espaço, com especial atenção para a sua ressignificação pelos usuários das escolas, principalmente os alunos. A pesquisa foi desenvolvida em duas dimensões: análise do referencial teórico e pesquisa empírica. A pesquisa teórica percorreu autores de diversas áreas do conhecimento (Educação, Arquitetura, Psicologia, Filosofia e Geografia) que trouxeram importantes contribuições para esta reflexão. A pesquisa empírica foi realizada numa escola pública estadual da cidade de São Paulo, construída no período da Primeira República e com 104 anos de existência e tombada pelo CONDEPHAAT (Conselho de Defesa do Patrimônio Histórico, Arqueológico, Artístico e Turístico da Secretaria da Cultura do Governo do Estado de São Paulo) pelo valor histórico, cultural e arquitetônico de seu prédio. Foram utilizados como procedimentos de coleta de dados a observação em campo e o registro iconográfico (fotografias e desenhos), entrevistas livres e registro de depoimentos espontâneos dos funcionários da escola e uma entrevista semiestruturada e em grupo com alunos do $8^{\circ}$ ano do Ensino Fundamental todos com o objetivo de identificar e compreender a constituição, organização, uso, vivências cotidianas, apropriações e significados do espaço escolar. Desta forma, compôs-se uma reflexão que traz contribuições para o entendimento do espaço como construção humana e, como tal, lugar que carrega significações não aleatórias, mas passíveis de serem transformadas e recriadas por meio da diversidade de apropriações que pessoas reais fazem dele; lugar que impõe constrangimentos (conformando corporeidades e mentalidades) e impinge controle e disciplina ou que pode estar "aberto" à experimentação criativa; lugar impregnado pela(s) cultura(s), mas que também é "habitado" por percepções e vivências pessoais; e, no caso da escola, materialidade que propõe, ainda, sentidos sobre a escola e o conhecimento e sobre sua função em nossa sociedade.

Palavras-Chave: 1. Espaço escolar; 2. Relação aluno-escola; 3. Semiótica da arquitetura; 4. Cultura escolar; 5. Escola Pública; 6. Escolarização. 



\begin{abstract}
CASTILHO, Clarissa. School space as a symbolic mediator: culture, experience, meaning and senses. 2014. 345 p. Doctoral dissertation in Education - Faculdade de Educação, Universidade de São Paulo, São Paulo, 2014.

From Vygotsky's construct of symbolic mediation, understood as intrinsic to the human psychological and cultural development, this qualitative study has investigated the school environment as a mediator of meanings and senses of school, both by means of what the school's architectural configuration proposes and by the experience and uses that it allows, and has focused on the school's resignification by its users, especially students. The study included two dimensions: an analysis of the theoretical framework and empirical research. The theoretical research included authors from different areas of knowledge - education, architecture, psychology, philosophy and geography -, who brought important contributions to this discussion. The empirical research was conducted in a state public school in Sao Paulo city. Built 104 years ago, during the First Republic, such school was listed by Conselho de Defesa do Patrimônio Histórico, Arqueológico, Artístico e Turístico (CONDEPHAAT - Council for the Defense of Historical, Archaeological, Artistic and Touristic Heritage) of São Paulo State Department of Culture, for the historical, cultural and architectural value of its building. As for data collection, I used field observation and iconographic records (photographs and drawings), free interviews and recording of spontaneous comments from school officials and a semistructured group interview with 8th grade students, aiming to identify and understand the constitution, organization, use, and daily experience and meanings of the school space. Thus, I have written a reflection that brings contributions to the understanding of space as a human construction and, as such, as a place that carries meanings that are not random and can be transformed and recreated through the diversity of appropriations by real people; a place that imposes constraints (conforming mentalities and corporealities) and enforces control and discipline or that may be "open" to creative experimentation; a place impregnated with culture(s), but also "inhabited" by our personal perceptions and experiences; and, in the case of school, materiality which also proposes senses of school and knowledge and about its role in our society.
\end{abstract}

Key words: 1 . School space; 2. School-student relationship; 3. Semiotics of architecture; 4. School culture; 5. Public School; 6. Schooling. 



\section{LISTA DE SIGLAS}

\begin{tabular}{|c|c|}
\hline $\mathrm{ABNT}$ & Associação Brasileira de Normas Técnicas \\
\hline CEBRACE & $\begin{array}{l}\text { Centro Brasileiro de Construções e Equipamentos } \\
\text { Escolares }\end{array}$ \\
\hline CEU & Centro Educacional Unificado \\
\hline CIAC & Centro Integrado de Apoio à Criança \\
\hline CIEP & Centro Integrado de Educação Pública \\
\hline CONDEPHAAT & $\begin{array}{l}\text { Conselho de Defesa do Patrimônio Histórico, } \\
\text { Arqueológico, Artístico e Turístico (Secretaria da } \\
\text { Cultura - Governo do Estado de São Paulo) }\end{array}$ \\
\hline CONESP & $\begin{array}{l}\text { Companhia de Construções Escolares do Estado de } \\
\text { São Paulo }\end{array}$ \\
\hline DOE & Diário Oficial do Estado \\
\hline DOP & Departamento de Obras Públicas \\
\hline $\mathrm{EE}$ & Escola Estadual \\
\hline EEPG & Escola Estadual de Primeiro Grau \\
\hline EEPSG & Escola Estadual de Primeiro e Segundo Graus \\
\hline $\mathrm{EF}$ & Ensino Fundamental \\
\hline EF I & Ensino Fundamental - Ciclo I $\left(1^{\circ}\right.$ ao $5^{\circ}$ ano $)$ \\
\hline EF II & Ensino Fundamental - Ciclo II $\left(6^{\circ}\right.$ ao $9^{\circ}$ ano $)$ \\
\hline EM & Ensino Médio \\
\hline ETEC & Escola Técnica Estadual \\
\hline FDE & $\begin{array}{l}\text { Fundação para o Desenvolvimento da Educação } \\
\text { (Secretaria da Educação do Estado de São Paulo) }\end{array}$ \\
\hline FECE & $\begin{array}{l}\text { Fundo Estadual de Construções Escolares (Governo } \\
\text { do Estado de São Paulo) }\end{array}$ \\
\hline FMI & Fundo Monetário Internacional \\
\hline FUNDESP & $\begin{array}{l}\text { Fundo de Desenvolvimento da Educação do Estado } \\
\text { de São Paulo }\end{array}$ \\
\hline FUNDESCOLA & Fundo de Fortalecimento da Escola \\
\hline GE & Grupo Escolar \\
\hline IPESP & Instituto de Previdência do Estado de São Paulo \\
\hline LDB & Lei de Diretrizes e Bases da Educação \\
\hline MEC & Ministério da Educação (Governo Federal - Brasil) \\
\hline PCN & Parâmetros Curriculares Nacionais \\
\hline PNE & Plano Nacional de Educação \\
\hline SOP & Superintendência de Obras Públicas \\
\hline UNESCO & $\begin{array}{l}\text { United Nations Educational, Scientific and Cultural } \\
\text { Organization }\end{array}$ \\
\hline
\end{tabular}

